\title{
Territorial Resources of Baikal Zone: Project Development Methodology
}

\author{
O Arkhipkin ${ }^{1}$, A Lapshin ${ }^{2}$, S Golik ${ }^{3}$ \\ ${ }^{1}$ IIEL ISU, Ulan-Batorskaya, 6, 664082 Irkutsk, Russia \\ ${ }^{2}$ IIEL ISU, Ulan-Batorskaya, 6, 664082 Irkutsk, Russia \\ ${ }^{3}$ IIEL ISU, Ulan-Batorskaya, 6, 664082 Irkutsk, Russia \\ E-mail svetlago@id.isu.ru
}

\begin{abstract}
The main goal of the study is to form the methodological approaches in order to create a unified concept of socio-economic development of the territorial resources of the Baikal zone in terms of severe environmental restrictions; study and analysis of inertial factors; current trends in the transformation of the territorial and sectoral structure of the Baikal zone as a taxonomic subregion of the Baikal and Transbaikalia territory It was revealed that the main dominant in relation to the territorial resources is environmental protection. This limits both at present and in the future the effective use of the resource potential of the territory, since the methodology of the program of economic, economic and social evolution of the territory has not been formulated yet in the paradigm of the "new" economy where the traditional resources acquire new qualities via innovative technologies, including the quality of environmental feasibility. The article defines a set of industries that has been identified and whose development in Industry 4.0 and Agricilture 4.0 format, not disrupting the homeostasis of the territory, can serve as attractors of the socio-economic development of the unique territory of the Baikal zone. The article justifies that there is a necessity to distinguish the Baikal zone into "subadministrative" district in relation to the Irkutsk Oblast and Republic within the aquatic regions of Lake Baikal. The creation of the scientific and methodological Baikal center at the federal level, the transfer of managerial functions of the Baikal zone to a state corporation with the authority to administer a territory with quasi-legislative and quasi-judicial functions will help to solve the problems. The proposals about sources of financing for the implementation of the proposed Concept of socio-economic development of the Baikal zone are presented in the article.
\end{abstract}

Retrospectives of the contemporary problems of the efficient use of the territorial resources of the Baikal zone refer to the Program for the Development of Productive Forces of Eastern Siberia, and they go back to the 1930s to the Angarsk Bureau of the USSR State Planning Commission. A unique combination of natural resources in their territorial meaning: spatial, fuel and energy, mineral, forest, water was the resource justification for the implementation of this Program. This predetermined the economic specialization of the region - fuel and energy, non-ferrous metallurgy, forestry and timber chemistry. The spatial scale of the territory was estimated as potentially sufficient for the concentrated distribution of production capacities of any characteristics. In modern terminology, it is identical to the concentrated placement of harmful or environmentally hazardous industries [1]. 
In this context, Lake Baikal was considered as a practically unlimited water resource of the territory for the development of the industrial and production sphere of the region. Approximately in the same way, the potential of biological resources of Lake Baikal and the Baikal zone was also estimated.

Nevertheless, if we determine the methodological ideology of that period of large regional projects implementation both in Russia and abroad it is largely correlated with the concept of geographical possibilism in its socio-economic form. But in the last third of the twentieth century the concept of environmental imperative appears and begins to dominate which institutionalizes the contradictions between market-economic and socio-ecological development models of global, regional and local levels.

It is generally recognized that the environmental component and environmental restrictions are a constant of civilizational development in any form, and last but not least, of socio-economic development. Therefore, it is impossible to ignore the environmental component of territorial development, especially in the regional format. It is also unacceptable to interpret the correlation of ecology and economy as the antinomy of "good" and "evil".

The removal of the territories of the Baikal zone from the economic turnover of the regions cannot be considered rational even taking into account the uniqueness of the object or on the basis of the highest environmental reproduction considerations, because the effectiveness of traditional raw materials and industrial resources is subject to audit by post-industrial and information forms of socioeconomic development, and the ecological resources of the territory are transformed into the resources of the intangible substance of social reproduction and the economic process.

Over the past twenty years, at the administrative-legal and economic-practical level, the repeated attempts have been made to harmonize and optimize the use of the Baikal zone. For example, the creation of special economic zones of tourist-recreational type in the Irkutsk region (2007) and in the Republic of Buryatia (2009), closing Baikal Pulp and Paper Mill in 2013, the development of environmental zones of the territory (Baikal, Barguzinsky, Baikal-Lensky reserves, etc.) as well as the tightening of legislative standards, etc.

Despite the generally recognized actualization of socio-economic problems development correlation and environmental sustainability and an extensive toolkit aimed at solving them - practical results, although partly remove the severity of the problems, but at the same time they give the rise to new ones.

Closing the BPPP in its consequences has the need for waste disposal (6 million tons) which has been discussed for more than five years and will cost 2.6 billion rubles, with some of the funds have already been spent. But neither technology nor organizational structures of this project have been determined. Along with this, the prospects and directions of socio-economic development of the city of Baikalsk where BPPPM was a city-forming enterprise remain uncertain up to day. The creation of the SEZ (special economic zone) implies wider possibilities of using the available resources, including land use which cause the abuse by both residents and non-residents of these territorial and economic entities, when the land began to be used for other purposes and not without harm to the ecology of Lake Baikal. In addition, new economic entities in the territories of the SEZ began to occupy "niches" traditionally owned by the local businesses and the local population. In general, the functioning of the Baikal SEZ did not give the expected results in both socio-economic and financial-budgetary perspectives, despite a significant infusion of state and financial resources, therefore, clustering projects of the Baikal zone are being formed for their resuscitation.

The standardization of environmental management standards and environmental activities led to contradictions in the goal-setting of the interests of the authorities, business and the public.

The situation is complicated by the fact that Lake Baikal is a transboundary water area of two regions - the subjects of the Federation - the Irkutsk region and the Republic of Buryatia. As independent regions and entities, each has its own set of socio-economic parameters that determines the regional development priorities specifics and hierarchy, including with respect to the territorial resources of Lake Baikal. 
Taking into account the current situation and the negative trends of its further development, it seems appropriate to reconstruct the territorial organization and mechanism for managing the territorial resources of the Baikal zone.

First of all, it is necessary to specify the spatial limits of what is defined in this text under the term the "Baikal zone". In the regional science the majority of concepts have polysemantic meaning and various levels of scaling (region, district, area, locality, etc.). The use of the term "zone" as a definition of space is not always correct (Western or Eastern economic zone, Arctic zone) in relation to its original meaning of zone (Greek) as belt. In our case the expression Baikal zone or the Baikal economic zone terminologically denotes the territory adjacent to or surrounding Lake Baikal. It allows to distance oneself from the concept of territorial resources of the Baikal region as a combination of three subjects of the Russian Federation adjacent to Lake Baikal, the total area of which is $1558.1 \mathrm{~km}^{2}$, This fact cannot be considered to be operational for research and solution of the problems related to Lake Baikal and its territorial resources. At the same time, the use of the concept 'the Baikal zone' allows to make the demarcation of this territorial formation from all others and to increase the degree of concentration of the Baikal problem. In this case, we are not talking about the classical process of taxonization as the process of establishing a hierarchy of structural relationships between territorial entities on the basis of their equivalence or subordination. The identification of the Baikal zone as a territorial unity is based on general (universal) principles of zoning of both natural and socio-economic genesis. In the broadest sense, a region is a set of features that have a certain homogeneity and thereby differ from other territorial entities. It is a historical territorial socio-natural integrity that has the properties of self-sufficiency resource for its natural and socio-economic simple or extended reproduction in a more expanded form. In this context, the identification of the Baikal zone and the water area of Lake Baikal as a specific district (region) seems quite justified, because it methodologically contains all the immanent qualities necessary for its identification. It is the social and natural homogeneity of the territory in terms of belonging to a unique object and differentiation from other territorial entities, not related to this uniqueness. Based on this approach to the taxoning, the territory, for example, of the Taishet district, can be assigned to the Baikal region in a very conditional way, since the distance from its regional center to Krasnoyarsk (the center of Yenisei Siberia) is $394 \mathrm{~km}$, and to Irkutsk (the center of Baikal) is $662 \mathrm{~km}$.

Therefore, it seems appropriate to determine the external borders of the Baikal zone in accordance with the administrative boundaries of the aquatic regions of the Irkutsk region and the Republic of Buryatia, which include the Irkutsk, Slyudyansky and Olkhonsky districts of the western coast of Baikal and the Kabansky, Pribaikalsky, Barguzinsky, and North-Baikal districts of the eastern coast.

Thus, the territorial parameters of the Baikal zone will amount to 134.8 thousand $\mathrm{km} 2$ with a population of 289.4 thousand people. If we add to this the water area of the lake $\left(31,722 \mathrm{~km}^{2}\right)$, then the total area of this territorial formation will be 166.5 thousand $\mathrm{km} 2$, which is comparable with the territorial resources of such subjects of the Federation as Altai Krai (167.9 thousand km2) and Primorsky Krai (164.6 thousand km2).

Currently, there is no need to complicate the taxonomic system by separating the Baikal zone into a formal region or region existing de jure or with a claim to the status of an independent territorialadministrative unit. But a region can be informal if it is formed on any objective grounds as the result of special studies of the territorial structure.

In our case, the allocation of the Baikal zone has not only scientific, methodological, but also organizational and practical significance, since a new object of territorial development and management is emerging.

The global level objectifies Lake Baikal as a unique natural object that has the status of a world (planetary) natural heritage territory (12th session of UNESCO, the World Heritage Committee, December 5, 1996), which should be preserved. Therefore, it minimizes the forms and types of economic and economic activity of the Baikal region territories before recreation and tourism. 
The national (all-Russian) level follows the existing international trend to protect and preserve the object from anthropogenic impacts declared in the Federal Law No. 94-FZ "On the Protection of Lake Baikal” (with amendments and additions).

The regional level - Baikal - is an object limited in its uniqueness by its involvement in economic activity, primarily as a water, fishery, tourist and recreational resource, etc. Its use is regulated, on the one hand, by rational environmental management standards set by the vertical authorities, on the other hand, by the need to implement regional goals and objectives, including financial and budgetary.

The local level - Baikal - is not a unique object, but a factor in the environment and livelihoods; Baikal macro-uniqueness comes into antagonism between local and traditional living conditions (including industrial and economic) and externally brought transformations.

The differentiation of objectivity leads to the differentiation of actors involved in the regulation and management of environmental management and socio-economic development, their goal-setting, tasks and means of implementation [2].

It is natural and justified that the main actor is the state which is responsible for the legislative background and federal target programs, in particular, "Protection of Lake Baikal and the SocioEconomic Development of the Baikal Natural Territory for 2012 - 2020".

At the same time, the implementation of this Program is in sphere of environmental activities and the actual socio-economic development has fallen behind its practical activities, because the objectives of the Program are defined as "protecting Lake Baikal and protecting the Baikal natural territory from the negative impact of anthropogenic, industrial and natural factors". Its sociality is defined here by the thesis "ensuring the protection of the territory and population from emergency situations."

There is no use of criticizing the environmental (ecological) ideology of the Federal Center. It should be noted that the achieved results of the Program appeal to the need for further development of the Baikal natural territory on slightly different methodological grounds.

In its ontological and territorial content, ecology is not a sphere of environmental activity, but the reproduction of socio-economic systems via the consumption of resources of both natural and social genesis which involves the establishment of quantitative and qualitative consumption volumes to preserve the homeostasis of the territory. Such approach, on the one hand, does not exclude the involvement of the territory's natural resources for production and social consumption in the economic turnover, and, on the other hand, it leads to the necessity for strict and subtle control over the processes of production and resource consumption.

This involves the creation of a single socio-economic concept for the development of the productive forces of the Baikal zone. It can be recognized as a paradox, but such a concept is still lacking, in spite of the significant number of specialized institutions, such as the Baikal Institute of Nature Management SB RAS, the Baikal Research Center (ANO), Irkutsk State University and its department, the Institute of Biology ISU, Limnological Institute SB RAS and many others.

As it follows from the above, economic and social problems of development are not included in the scientific priorities of these organizations and institutions, as they are mainly focused on the development of environmental management models which is clearly not enough in modern conditions.

Thus, it is possible to conclude that the authorities and the management, as well as in the scientific community, have no vision of what the territory's economy will be in spatial, sectoral, structural relations in the medium, long, and evolutionary perspective.

Taking into account the international, national and regional scale of the importance of the Baikal zone for the formation of a unified strategic concept for the socio-economic development of the territory, it is necessary to create a Center for the development, planning and program's implementation at the federal level under the Ministry of Economic Development. Usually the Ministry of Natural Resources has traditionally had authority over the Baikal issues as part of its activities "Regional Development", aimed at regulating the socio-economic development of the constituent entities of the Russian Federation and in the field of spatial planning.

The strategic objectives of the Center should include: 
- determination of the balance capacity of the territory of the Baikal zone and the main directions of its socio-economic development;

- comprehensive studies of the territory's resources and the calculations, characterizing the effectiveness of their involvement in the national economy,

- development of an integrated system of scientific ideas of long-term areas, layered and integrated socio-economic development of the territory;

- determination of the forms of territorial organization of the economy, adequate to the specific features of the Baikal zone;

- harmonization of environmental constraints and opportunities for socio-economic development for expanded social reproduction.

The principle of priority of regional and local socio-economic goals and functions, i.e. the development should be oriented in those directions. It would give the maximum effect for the local population. Advantages should be given to those activities that would solve not only current problems, but also create future groundwork.

The formation of the Concept structure should come from three basic elements.

1. The rationale for the set of industries that should be developed in the Baikal zone from the standpoint of the interests of regional and local levels. It can conditionally be called branches of regional specialization of the territory. Not only favorable conditions for their creation should be accepted as the main selection criteria, but also the evolving opportunities and needs of the future associated with technological, environmental, information and social transformations.

2. Territorial section and justification of the long-term territorial development policy of the Baikal zone. It means the simultaneous resolution of issues not only what and in what sequence to develop, but also where it is advisable to be done at different stages. It is necessary to formulate a strategy for the territorial organization and location of production and social facilities and infrastructure.

3. Assessment of external and internal conditions for the implementation of long-term development goals. In this case, "external conditions" should be understood as what resources, primarily investment, the state will be able to have at different stages, as well as other significant factors and circumstances of national importance that will stimulate or vice versa restrain the territory development. By "internal conditions" is meant an assessment of local opportunities to create the appropriate living conditions for the inhabitants of the territory.

The preliminary content of a long-term program can be summarized as follows.

The key role in the development of the Baikal zone will be given to unique recreational resources. This implies stringent requirements for a set of other industries, which were supposed to provide the territory with the most environmentally-friendly and high-quality products. When forming an already direct set of production, priorities can be set as follows.

It is already obvious that in the future the system-forming structure of the territory will be the tourist and recreational complex in all areas and forms of its potential realization, including medical and health and other segments.

At the same time, it is impossible to ignore the brunches and industries that are currently the basis for most administrative-territorial formations of the Baikal zone. The majority of them are agricultural, forestry and fisheries, providing or maintaining basic economic parameters, while tourist and recreational resources involved in the economic turnover are clearly not enough, and their financial and economic efficiency in comparison with the above-mentioned traditional ones is negligible.

Despite this, the prospects for the development of these areas of economic and economic activity in the unique format of the Baikal zone are not the subject of consideration by responsible organizational structures. The need to include this block of problems in the general Baikal topic of socio-economic development is obvious by the social significance of these industries for the local population.

It should be noted that a tendency of romantic illusion is starting to appear that the realization of the idea of spreading tourist and recreational activities throughout the territory of Lake Baikal will lead to the automatic solution of all environmental and socio-economic problems, and it is basically impossible in the spatio-temporal continuum of the territory. Therefore, the development of 
agriculture, forestry and fisheries should also be included in the concept of development of the Baikal zone.

Regardless of resource or industry development objects, it should be imperative that the uniqueness of the territory requires unique means and methods of its development, innovative and advanced production, technical and social technologies, the latest forms of spatial organization, which should ensure the maximum socio-economic effect [3] which correlates with the evolution of the economy into a "new economy", economy Industry 4.0 in its methodology.

The settlements of the Baikal zone currently have a rural profile of three types: agricultural settlements themselves, in which the inhabitants are predominantly engaged in agricultural labor; nonagricultural settlements, where residents perform discrete territorial functions - forestry, water, transport, service villages at medical institutions, single buildings; agro-industrial settlements as a combination of the two previous types as a result of the emergence and development of agricultural processing industry in rural areas.

The existing structure of settlements should be considered productive for its innovative development in the Agriculture 4.0 trend, focused on the ecological and economic type of resource development, smart farming technologies with the introduction of nanobiotechnology, off-ground and vertical plant growing technologies, organic agriculture and the use of all modern and future achievements NTP (satellite navigation systems, drones, 3D printing capabilities of food products, deployment of the Internet, blockchain, etc.) [4].

New technologies present new requirements for territorial forms of economic organization. The cluster theory, which is actively developed and implemented at the regional level, including in the Baikal zone both in the Irkutsk region and in the Republic of Buryatia, is recognized as the most popular theory of territorial socio-economic development in relation to its innovative forms. A significant remark on the policy of clustering of these entities should be considered the fact that it is aimed exclusively at the tourism sector. Although the logic of sustainable development of the territory implies extending the cluster approach to other areas of economic action, primarily agricultural, forestry and water management, it is therefore necessary to develop a set of methods aimed at creating mechanisms to stimulate the development of these industries in a cluster format [5].

Projected areas of technological and territorial development of the Baikal zone should also be projected onto its social sphere. High technologies also impose higher demands on labor and social resources. It implies the higher growth rates of the human capital potential of the territory [6]. The needs of population will increase to the level of comfort of life and livelihoods along with the increase in the life quality of the population [7].

Therefore, the prospects for the development and planning should contain directions for the urbanization of settlements in the Baikal zone as an intensification of the transfer of economic, economic and sociocultural forms of activity characteristic of cities, and an increase in the specific gravity of these forms in the reproduction of socio-territorial communities. It will gradually change the nature of labor, technical and technological equipment, areas of employment, size of settlements, internal and external relations, communications, interests and needs of people and means of satisfying them, welfare, etc. It means the changes of the level of life.

The separation of the Baikal zone into a relatively independent spatial entity, or into a "subregion" as a designation of the place in the territorial aggregate of the Baikal territories of two constituent entities of the Federation, actualizes the contradictions between the administrative-territorial and sectoral management [8].

In the specifics of the Baikal zone, this is manifested in the fact that the Irkutsk region and the Republic of Buryatia have different points of view in using the resource potential of Lake Baikal as a water body and adjacent territories: water resources and hydropower; bioresources (problems of quotas, sport and recreational fishing); forest resources associated with restrictions, assumptions and insufficiently regulated conditions of their use; land resources - various approaches and legislative support for land use; various assessments of the social effectiveness of investment projects for the 
local population, etc. Ultimately, this leads to a conflict of interest regarding the transboundary territory of the two regions which Lake Baikal consists of.

In many areas of activity in the transboundary space, administrations and even the scientific communities of the Irkutsk region and the Republic of Buryatia can have diametrically opposed attitudes, which causes the involvement of environmentalists, energy companies, business structures, and the public of neighboring regions into conflicts. In the absence of mechanisms for proactive problem solving and consensus building, most disputes and disagreements are resolved either through the courts or through the intervention of the federal government.

This state of affairs requires a different management system for the Baikal zone. In the general methodology of regional policy in a complex federal state, there is an opinion that the logic of regional development should go beyond administrative boundaries. Based on this, the creation of a unified management and control structure of an extraterritorial nature in relation to the administrative functions of the Irkutsk region and the Republic of Buryatia should be recognized as optimal for the Baikal zone.

The organization and structure of such a governing body should also be developed by the abovementioned Center for the development of a unified Concept for Socio-Economic Development under the Government of the Russian Federation and have the status of a State Corporation or Administration of the Baikal Zone (hereinafter referred to as the Corporation). This Corporation should be headed by a council appointed at the government level under control of the Federation Council.

In order to form a common legal basis for relations between subjects of the socio-economic and environmental sphere, it is possible for the Corporation to transfer a certain amount of quasilegislative and quasi-judicial functions in order to regulate these strategically important areas and resolve contradictions and disagreements by extra-judicial means, especially when the state does not consider it directly legitimate to intervene into the conflict of interests of territorial entities.

Preliminarily, it seems advisable to create three divisions within the Corporation's structure that monitor and develop the territory's water resources; land resources; socio-economic facilities.

It is possible to finance the implementation of the project at the expense of the federal Government, through the placement of loans, and at the expense of loans from international interested funds and financial institutions.

The powers of the Corporation should include: financial assistance to the municipalities where the development facilities are located; the acquisition of the ownership of the socio-economic facilities necessary for its functioning; Regulation of income of entities participating in the Corporation.

Three vectors should be laid in the goal-setting of the corporation: the implementation of a multipurpose project in the Baikal zone; economic development of the Baikal zone; social changes aimed at increasing the quality of life of the population of the Baikal zone.

It is already possible to determine the sources of financing, the nature of relations between federal, regional and municipal bodies and other interested structures at the design stage.

The creation of such a Corporation corresponds to the function of a federal state represented by the government to carry out territorial development through its regional component. This can be confirmed by the Far East Development Project, the Arctic project. The project of socio-economic development of the Baikal zone should be presented as a continuation of this trajectory.

The problems of using the territorial resources of Lake Baikal and the possibilities of their inclusion in the socio-economic reproduction process are a reflection of the problems of the civilizational movement in the post-industrial paradigm of overcoming the dichotomy "economic" "environmental".

Therefore, the development methodology of the Baikal zone should be based on minimizing the environmental risks of using a unique natural site and maximizing its economic efficiency to maintain and preserve natural, social, historical and cultural homeostasis. 
The methodological scope of the problems necessitates an appropriate scale of organizational forms, means, methods, tools, which might be possible only on the basis of the paternalistic functions of the state

The creation of the federal center for the development of a strategic concept for the development of the Baikal zone, capable of accumulating all the specialized intellectual resources specialized in this area, suggests the possibility of formulating scientifically based areas of practical activity to achieve this goal in the spatial, temporal, sectoral and organizational and legal continuum.

For the effective implementation of the set tasks, an adequate management structure is required in the form of a state corporation that initiates and supports the innovative-technological and environmental-social development trend.

The management functions of the Corporation will make it possible to unify the inconsistencies and contradictions caused by the administrative-territorial division of the Baikal zone between the Irkutsk region and the Republic of Buryatia. The methodological possibility of this is due to the fact that the territory of the Baikal zone (as an "above subjective" entity) has borders that correspond to historical and cultural, including economic and environmental traditions.

In the regional-political aspect, the separation of the Baikal zone into a "subregion" and the creation of managerial autonomy creates the conditions for legitimizing the interaction of federal authorities and local governments in realizing the goals and objectives of the national, regional and local levels.

\section{References}

[1] Felshin G 1988 Economics of Angara: Problems and Prospects. (Irkutsk: East.- Sib. Book Publishing House) p 206.

[2] Svetnik N 2018 Methodological Issues of Organizing Subject-Object Interaction of Interested Groups in the Development of Industrial Policy in the Region. Russian Business. Volume 19. No. 10. p 2835-48.

[3] Ilyina I, Zharova E, Agamirova E and Kamensky A 2018 Innovative Development of Russian Regions. Regionology. Volume 26. - No. 2. p 230-255.

[4] Anishchenko A and Shutkov A 2019 Agricilture 4.0 as a Promising Model for the Scientific and Technological Development of the Agricultural Sector of Modern Russia. Food Policy and Security. Volume 6. - No. 3. p 129-140.

[5] Groshev A and Pelikhov N 2019 Cluster Initiatives: Systemic Features of Formation, Development and Management. Leadership and Management. Volume 6. - No. 2. p. 91-106.

[6] Gataullin R 2017 Technological Breakthrough as the Basis for Overcoming the Polarization of the Socio-Economic Development of the Territory. Economics and Entrepreneurship. No. 8-2 (85-2). p 370-375.

[7] Vartanova M and Bezverbny V 2019 Improving the Level and Quality of Life of the Population is the Main task of Sustainable Development of Rural Territories. Economic Relations. Volume 9. No. 3. p 1925-38.

[8] Akberdina V 2018Multisubject Industrial Policy (Yekaterinburg: Institute of Economics, Ural Branch of the Russian Academy of Sciences) p. 356. 